\section{AL-AZHAR Dental Journal}

F o r
The Official Publication of The Faculty of Dental

Medicine For Girls,

Al-Azhar University Cairo, Egypt.

Print ISSN 2537-0308 • Online ISSN 2537-0316

ADJ-for Girls, Vol. 7, No. 4, October (2020) - PP. 537:546

\title{
Effect of Abrasive Containing Whitening Dentifrices on Surface Characteristics and Color Stability of Two Aesthetic Restorative Materials
}

\author{
Asmaa A. $\operatorname{Ramadan}^{1 *}$, Mohamed S. Ali' ${ }^{2}$, Rania E. Bayoumi ${ }^{3}$
}

Codex : 67/20.10

azhardentj@azhar.edu.eg

http://adjg.journals.ekb.eg

DOI: $10.21608 /$ adjg.2020.14152.1178

Restorative Dentistry

(Removable Prosthodontics, Fixed

Prosthodontics, Endodontics, Dental

Biomaterials, Operative Dentistry)

\section{KEYWORDS}

Composite, color, Dentifrices,

Glass ionomer, Micro-hardness,

Roughness.

\begin{abstract}
Purpose: This study was designated to evaluate the effect of whitening dentifrices on surface characteristics and color Stability of two aesthetic restorative materials. Materials and Methods: A total of 180 specimen were prepared from two tested materials (Filtek Z350 resin composite and Equia forte glass ionomer with nano filled coat).The specimen were divided into three groups $(n=60)$. Group 1: hydrated silica containing tooth paste Group 2: calcium carbonate containing tooth paste, Group 3: trisodium phosphate containing tooth paste, each group was subdivided into two subgroups according to number of brushing duration $(1120,2240)$ cycles $(n=15)$.Each subgroup was further subdivided into three divisions according to the type of test performed (micro hardness, surface roughness, color stability) ( $n=5)$. All tests were done before and after brushing then the data were statistically analysed. Results: Baseline results revealed that resin composite has higher micro hardness, lower surface roughness and more color stability compared to glass ionomer. Regarding the effect of tooth paste; trisodium phosphate containing tooth paste recorded the higher micro hardness, lower surface roughness and more color stability among all tested groups. On other hand, brushing for eight weeks (2240cycles) showed significant decrease in micro hardness, increase in both surfaces roughness and color instability. Conclusion: Abrasive containing whitening dentifrices and number of brushing cycles have an influential effect on surface characteristics and color stability of composite and glass ionomer.
\end{abstract}

- Paper extracted from Master Thesis titled "Effect of whitening dentifrices on surface characteristics and color Stability of two aesthetic restorative materials"

1. Demonstrator, Dental Biomaterials Department, Faculty of Dental Medicine for Girls, Al-Azhar University, Cairo, Egypt

2. Professor, Head of Dental Biomaterials Department, Faculty of Dental Medicine for boys, Al-Azhar University, Cairo, Egypt

3. Assistant Professor, Dental Biomaterials Department, Faculty of Dental Medicine for Girls, Al-Azhar University, Cairo, Egypt

* Corresponding author email: drasmaaahmed15@gmail.com 


\section{INTRODUCTION}

Discoloration of esthetic restorative materials is one of the chief problems expressed by many patients. Discoloration of resin composite depend on intrinsic and extrinsic factors to which they are routinely exposed, these factors could be insufficient curing, water sorption, diet and intake of staining foods or abrasive containing tooth pastes ${ }^{(1-3)}$. The use of toothpastes that promote whitening by removing or controlling extrinsic stains present on tooth surface mechanically using abrasive particles has become common, abrasive agents incorporated in whitening tooth pastes may be trisodium phosphate, alumina, calcium carbonate, perlite, hydrated silica, sodium bicarbonate and calcium pyrophosphate. Each whitening tooth paste has a relative dentin abrasive effect (RDA), which is able to influence the wear and surface roughness of dental materials ${ }^{(4-6)}$.

Nanofilled resin composite was developed in attempt to produce a restorative material that could be used in both anterior and posterior restoration, achieving good mechanical properties, good initial polish $^{(7)}$. Recently, a new restorative system has been marketed that consist of a highly viscous conventional GIC with good particle size and polyacid distribution lead to high cross-linking GIC matrix and better physical properties compared to traditional GICs.in addition to a novel nano filled self-adhesive coating material which provides very low viscosity and high hydrophobicity justify the perfect seal of a GIC surface also it acts as a glaze to protect glass ionomer against abrasive wear. This is important in the first months until the GIC is fully matured and able to tolerate the intraoral stresses also it improve the esthetic properties of GICs ${ }^{(8,}$ ${ }^{9}$.Therefore, the study was designed to evaluate the effect of abrasive containing whitening dentifrices on surface characteristics and color stability of this newly developed aesthetic dental materials.

\section{MATERIALS AND METHODS}

I- Materials: The materials used in this study, their specification, composition, manufactures and batch numbers are summarized in table (1).

Table (1): Chemical compositions, manufactures, and batch numbers of materials used in this study

\begin{tabular}{|l|l|c|c|}
\hline \multicolumn{1}{|c|}{ Brand Name } & \multicolumn{1}{|c|}{ Composition } & Manufacturer & Lot Number \\
\hline $\begin{array}{l}\text { 1- Hydrated silica containing } \\
\text { tooth paste (signal complete). }\end{array}$ & $\begin{array}{l}\text { Hydrated silica, aqua (water), zinc citrate, perlite and } \\
\text { cellulose gum. }\end{array}$ & $\begin{array}{l}\text { Unilever, Mashrek, } \\
\text { Egypt. }\end{array}$ & ABN07 \\
\hline $\begin{array}{l}\text { 2. Calcium carbonate contain- } \\
\text { ing tooth paste (Colgate). }\end{array}$ & $\begin{array}{l}\text { Calcium carbonate, potassium sulphate, titanium diox- } \\
\text { ide, sodium bicarbonate, sulfate. }\end{array}$ & $\begin{array}{c}\text { Muttenz } \\
\text { Switzerland }\end{array}$ & 4132 \\
\hline $\begin{array}{l}\text { 3.Trisodium phosphate contain- } \\
\text { ing tooth paste. (close up) }\end{array}$ & $\begin{array}{l}\text { Trisodium phosphate, aqua, Mica, sodium fluoride, cel- } \\
\text { lulose gum. }\end{array}$ & $\begin{array}{l}\text { Unilever, Mashrek, } \\
\text { Egypt. }\end{array}$ & 11609 \\
\hline $\begin{array}{l}\text { 4- Filtek Z350 } \\
\text { Equia forte coat }\end{array}$ & $\begin{array}{l}\text { Matrix: UDMA,TEGDMA Bis- GMA resin, Bis-EMA resin } \\
\text { Fillers: Non-aggregated silica fillers (20nm) } \\
\text { b-Non-aggregated zirconia fillers( 4-11nm) } \\
\text { c)Aggregated silica, zirconia cluster filler: (20nm } \\
\text { silica,4nm zirconia) in size range0.6-1.4microns Filler } \\
\text { loading (79 wt. \%) }\end{array}$ & $\begin{array}{l}\text { GM ESPE } \\
\text { Germany }\end{array}$ & 533014 \\
\hline 5.Equia forte fill system and & $\begin{array}{l}\text { Equia forte fill: powder: Fluoroalumino silicate glass, } \\
\text { highly reactive glass particles, dispersed with in con- } \\
\text { ventional GI structure, with addition a higher molecular } \\
\text { weight poly acrylic acid powder. } \\
\text { Liquid: aqueous poly acrylic acid.Equia Forte coat: } \\
\text { consist of new cross linking monomer chemistry, nano } \\
\text { filled resin matrix with particle size(30-40nm),15\% } \\
\text { silica filler. }\end{array}$ & $\begin{array}{l}\text { GC Europe N.V } \\
\text { Interleuvenlaan33 }\end{array}$ & $180514 \mathrm{~A}$ \\
\hline
\end{tabular}




\section{II- Methods:}

\section{Preparation of specimens:}

A total of 180 Specimens of two investigated materials were prepared using Teflon mould with dimension of $\left(6 \mathrm{~mm}\right.$ diameter and $3 \mathrm{~mm}$ thickness ${ }^{(\mathbf{1 0})}$. The mould was slightly over-filled with the composite, mylar strip was placed over it, then another glass plate was placed over the strip and it was pressed to get rid of the excess composite. The curing time of composite was 40 seconds for each side by LED curing unit of $750 \mathrm{~mW} / \mathrm{cm} 2$ (Emitter Schuster, Rio Grande do Sul, Brazil) ${ }^{(11)}$. After curing, the specimens were polished using 600, 800 and1000 grits (Sof-Lex, 3M ESPE) polishing discs in a sequential manner. The specimens were washed for 2 minutes in distilled water to clear away any surface contaminants, then stored for 24 hours in $37^{\circ} \mathrm{C}$ distilled water ${ }^{(12)}$. Regarding glass ionomer specimens, they were prepared according to manufacturer instructions using the same Teflon mould used for composite specimens, then Equia Coat was applied using micro brush and photo cured for 20 seconds with LED curing unit.

\section{Baseline Measurements:}

\section{1- Microhardness testing:}

Vickers micro-hardness tester (Lanzhou Huayin Testing Instrument Co, Ltd. China) with a Vickers diamond indenter and with lens of 20X was used to measure surface micro-hardness for specimens. A load of $200 \mathrm{~g}$ was applied for 20seconds to the surface of the specimens. Three indentations placed over a circle and not closer than $0.5 \mathrm{~mm}$ to the adjacent indentations, were made on the surface of each specimen. Vickers hardness number was calculated from the following equation:

$$
\mathrm{VHN}=\frac{\operatorname{load}(\mathrm{N})}{\operatorname{area}\left(\mathrm{mm}^{2}\right)}
$$

\section{2- Surface roughness testing:}

\section{Profilometer:}

Surface profilometer (TR220 roughness tester, Pittsburg, PA, USA) was used to measure roughness (Ra).Three readings were taken for every specimen. The mean roughness was represented by the mean between the peaks and valleys registered, after the needle of device had scanned a stretch of $2 \mathrm{~mm}$ in length, with acut-off of $0.25 \mathrm{~mm}^{(13)}$.

\section{Atomic force microscope:}

Image microphotographs were taken by Atomic force microscope (AFM, Omicron UHV-VT-XA, Germany) to determine the nano-roughnessof investigated groups ${ }^{(14)}$.

\section{3- Color measurement: -}

Color change of the specimens were recorded using a reflective spectrophotometer (X-Rite, Germany). Measurements were made according to the CIE L*a*b* color space relative to the CIE standard illuminant D65 using white back ground. The color changes $(\Delta \mathrm{E})$ of the specimens were evaluated using the following equation: $\Delta \mathrm{E}=(\Delta \mathrm{L} * 2$ $\left.+\Delta \mathrm{a}^{*} 2+\Delta \mathrm{b}^{*} 2\right) \frac{1 / 2}{2}$ Where: $\mathrm{L}^{*}=$ lightness $(0-100)$, $\mathrm{a}^{*}=$ (change the color of the axis red/green) and $\mathrm{b}^{*}=(\text { color variation axis yellow/blue })^{(15)}$.

\section{Brushing of specimens:}

Three body tooth brushing wear testing was performed using a programmable controlled equipment using the newly developed four stations multimodal ROBOTA chewing simulator operated on servo-motor (AD-TECH TECHNOLOGY CO, GERMANY), the chewing simulator has four chambers simulating the horizontal and vertical motion together in the thermodynamic condition. Each of the chambers contains upper Jacob's chuck as tooth brush antagonist holder that can be tightened with a screw and a lower plastic specimen holder in which the specimen can be placed .The tested specimens were embedded in Teflon housing in the lower sample holder with the aid of cyanoacrylate 
glue. A load of $250 \mathrm{~g}$, which is equivalent to $2.5 \mathrm{~N}$ of brushing load was applied. The test was divided into different clinical simulation time as equivalent to 4 weeks (1120 cycles) and 8weeks (2240 cycles) brushing condition, accompanying slurry which was prepared by mixing a 2:1 ratio of distilled water and dentifrice ${ }^{(16)}$.

After brushing the previous testing procedures were repeated for all investigated specimens with the same sequences; micro hardness, surface roughness and color stability.

\section{Statistical analysis:}

The mean and standard deviation values were determined for each group in each test. To compare between more than two groups in non-related samples One-way ANOVA followed by Tukey post hoc test was used. Independent sample t-test was used to compare between two groups in non-related sample. The interactions between variables were tested by three-way ANOVA test. The significance level was set at $\mathrm{P} \leq 0.05$.

\section{RESULTS}

\section{Micro hardness}

Results revealed that there was a statistically significant difference between nano filled composite and glass ionomer $(\mathrm{p}<0.001)$ as indicated by one way ANOVA test. Baseline measurements revealed that Filtek Z350 recorded the highest mean micro hardness value $\left(98.23 \pm 1.58 \mathrm{~N} / \mathrm{mm}^{2}\right)$ compared to Equia forte glass ionomer that recorded (73.10 \pm 3.42 $\mathrm{N} / \mathrm{mm}^{2}$ ).After brushing, materials brushed with trisodium phosphate containing tooth paste showed highest micro hardness followed with calcium carbonate containing tooth paste and the lowest micro hardness recorded with materials brushed with hydrated silica containing tooth paste. There was significant decrease in micro hardness after eight weeks brushing (2240cycles) as illustrated in table (2).

Regarding to type of restorative materials, results showed that the lowest mean $(\mathrm{Ra})$ value was recorded for Filtek Z350 $(0.046 \pm 0.007 \mu \mathrm{m})$ followed by Equia forte GI $(0.118 \pm 0.025 \mu \mathrm{m})$. After brushing, restorative materials brushed with hydrated silica containing tooth paste recorded highest mean $(\mathrm{Ra})$ value followed with that brushed with calcium carbonate containing tooth paste while materials brushed with trisodium phosphate containing tooth paste showed least mean (Ra) value. On other hand, eight weeks brushing (2240cycles) revealed significant increase in surface roughness $(\mathrm{Ra})$ value as shown in table (3).

Table (2): The mean, standard (SD) values and level of significance $(p<0.05)$ of hardness $\left(\mathrm{N} / \mathrm{mm}^{2}\right)$ of different tooth pastes in different groups.

\begin{tabular}{|c|c|c|c|c|c|c|}
\hline \multirow{2}{*}{ Variable } & \multicolumn{3}{|c|}{ Composite } & \multicolumn{3}{c|}{ Glass ionomer } \\
\cline { 2 - 7 } & \multicolumn{3}{|c|}{ Hardness } \\
\cline { 2 - 7 } & Before brushing & After 1120 cycles & After 2240 cycles & Before brushing & After 1120 cycles & After 2240 cycles \\
\cline { 2 - 7 } & Mean \pm SD & Mean \pm SD & Mean \pm SD & Mean \pm SD & Mean \pm SD & Mean \pm SD \\
\hline \multirow{2}{*}{ Colgate } & $98.23^{\mathrm{a}} \pm 1.58$ & $98.90^{\mathrm{a}} \pm 0.66$ & $88.42^{\mathrm{a} \pm} 0.98$ & $73.10^{\mathrm{a}} \pm 3.42$ & $77.13^{\mathrm{a}} \pm 2.05$ & $65.57^{\mathrm{a}} \pm 2.57$ \\
\hline Signal & $97.23^{\mathrm{a}} \pm 1.39$ & $96.23^{\mathrm{b}} \pm 0.61$ & $76.93^{\mathrm{b}} \pm 1.48$ & $72.13^{\mathrm{a}} \pm 2.20$ & $72.47^{\mathrm{b}} \pm 1.63$ & $60.67^{\mathrm{b}} \pm 2.40$ \\
\hline \multirow{2}{*}{$\boldsymbol{p}$-value } & $96.23^{\mathrm{a}} \pm 0.55$ & $92.90^{\mathrm{c}} \pm 1.54$ & $69.73^{\mathrm{c}} \pm 3.09$ & $70.77^{\mathrm{a}} \pm 1.72$ & $67.10^{\mathrm{c}} \pm 1.42$ & $54.93^{\mathrm{c}} \pm 1.58$ \\
\hline
\end{tabular}

Means with different letters states for significant difference, mans with the same letter's states for non-significant difference. ${ }^{*}$; significant $(p<0.05)$ ns; non-significant $(p>0.05)$. 
Table (3): The mean, standard deviation $(S D)$ values and level of significance $(p<0.05)$ of roughness $(\mu m)$ of different tooth pastes in different groups.

\begin{tabular}{|c|c|c|c|c|c|c|}
\hline \multirow{4}{*}{ Variables } & \multicolumn{6}{|c|}{ Roughness } \\
\hline & \multicolumn{3}{|c|}{ Composite } & \multicolumn{3}{|c|}{ GI } \\
\hline & Before brushing & After 1120cycles & After 2240 cycles & Before brushing & After 1120 cycles & After 2240 cycles \\
\hline & Mean \pm SD & Mean \pm SD & Mean \pm SD & Mean \pm SD & Mean \pm SD & Mean \pm SD \\
\hline Close up & $0.046^{\mathrm{a}} \pm 0.007$ & $0.055^{\mathrm{a}} \pm 0.013$ & $0.163^{c} \pm 0.028$ & $0.118^{\mathrm{a}} \pm 0.025$ & $0.122^{\mathrm{a}} \pm 0.005$ & $0.275^{\mathrm{c}} \pm 0.053$ \\
\hline Colgate & $0.046^{\mathrm{a}} \pm 0.007$ & $0.057^{\mathrm{a}} \pm 0.006$ & $0.538^{\mathrm{b}} \pm 0.034$ & $0.118^{a} \pm 0.025$ & $0.121^{\mathrm{a}} \pm 0.008$ & $0.655^{\mathrm{b}} \pm 0.070$ \\
\hline Signal & $0.046^{\mathrm{a}} \pm 0.007$ & $0.063^{\mathrm{a}} \pm 0.008$ & $0.940^{\mathrm{a}} \pm 0.242$ & $0.118^{\mathrm{a}} \pm 0.025$ & $0.125^{\mathrm{a}} \pm 0.004$ & $1.305^{\mathrm{a}} \pm 0.103$ \\
\hline p-value & 1ns & $0.474 n s$ & $<0.001 *$ & 1ns & $0.653 n s$ & $<0.001^{*}$ \\
\hline
\end{tabular}

Means with different letters states for significant difference, mans with the same letter's states for non-significant difference $^{*}$; significant $(p<0.05) \quad n s ;$ non-significant $(p>0.05)$.

\section{Roughness:}

\section{Atomic Force Microscope results:}

(Figure 1\& 2) show 3-D microphotography of the testedgroups before brushing. As viewed in (Figure1), resin composite reveals nearly uniform surface texture with smooth elevations and shallow valleys. Mean while (figure 2)glass ionomer show pointed elevations with some shallow valleys. (Figure 3\&4) show 3-D microphotography of the tested groups after brushing for eight weeks with

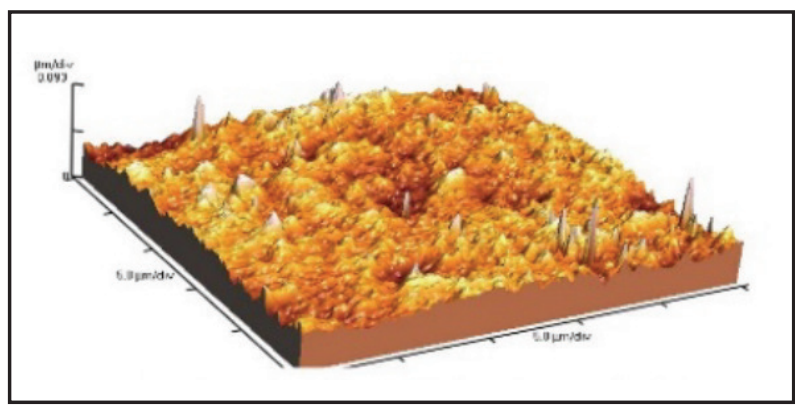

Figure(1) 3-D microphotograph of resin composite before brushing with mean surface roughness (Ra) 7.776. nm hydrated silica containing tooth paste.(Figure 3) shows AFM 3D image of resin composite,it reveals surface texture had irregularities,prominent sharpened peaks and deep valleys.(Figure 4) shows AFM 3D image of glass ionomer,it reveals more prominent sharpened and pointed peaks with deep,wide valleys.(Figure 5) shows surface texture had prominent spiky-like structure. (Figure 6) shows prominent sharpened peaks. (Figure 7) shows few numbers of shallow valleys. (Figure 8) shows broaded elevations and uniform ground.

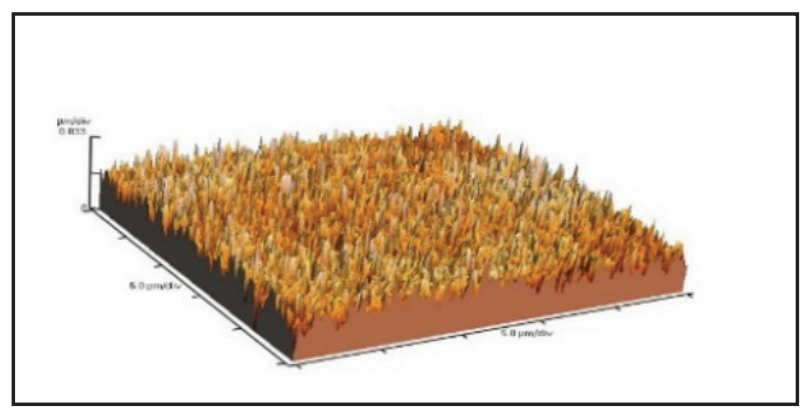

Figure(2) 3-0 microphotograph of glass ionomer with coat before brushing with mean surface roughness $(\mathrm{Ra})=$ $8.71 \mathrm{~nm}$. 


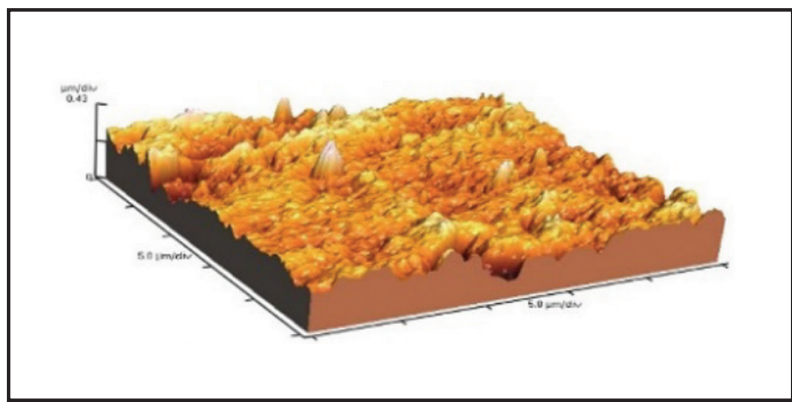

Figure (3) 3-D microphotograph of resin composite after brushing with signal for 2240 cycles mean surface $\operatorname{roughness}(\mathrm{Ra})=60.99 \mathrm{~nm}$.

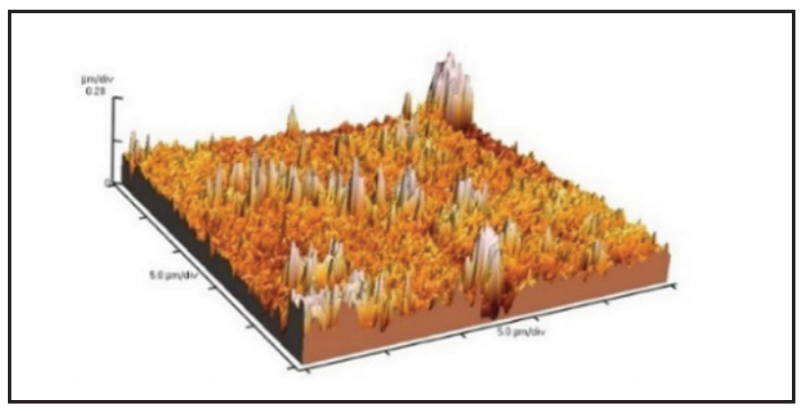

Figure (5) 3-D microphotograph of resin composite after brushing with Colgate for 2240cycles with mean surface roughness $(\mathrm{Ra})=32.30 \mathrm{~nm}$.

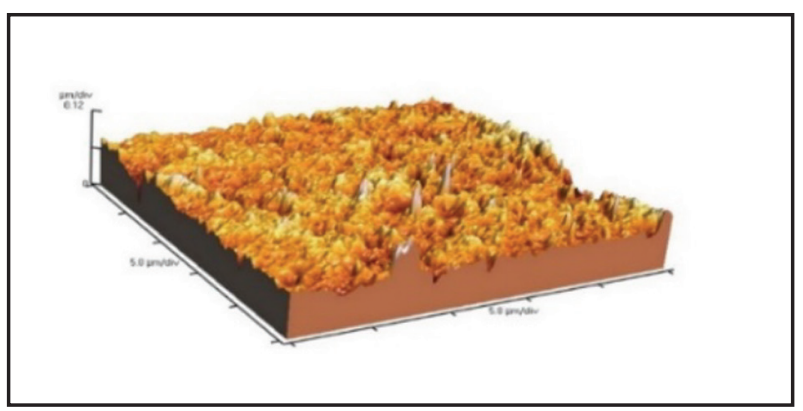

Figure(7) 3-D microphotograph of resin composite after brushing with Close up for 2240 cycles with mean surface roughness $(\mathrm{Ra})=12.86 \mathrm{~nm}$.

\section{Color results:}

Results revealed that there was statistically significant difference between Filtek Z350 and Equia forte GI, GI record higher color change than composite, GI brushed with hydrated silica containing tooth paste show highest color change

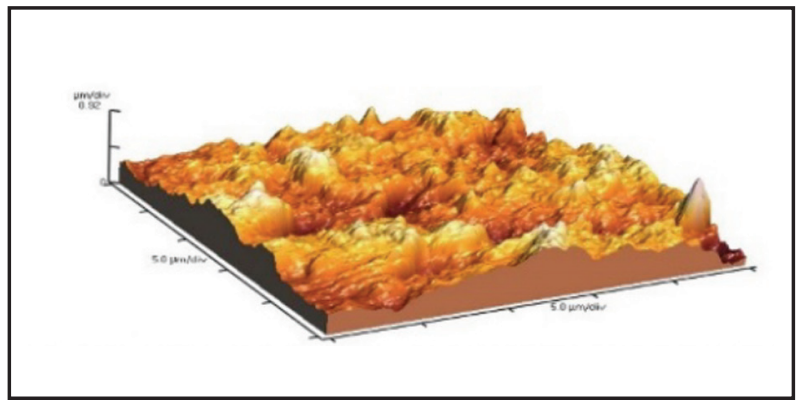

Figure (4) 3-D micro photograph of glass ionomer after brushing with signal for 2240cycles mean surface roughness $(\mathrm{Ra})=201.4 \mathrm{~nm}$.

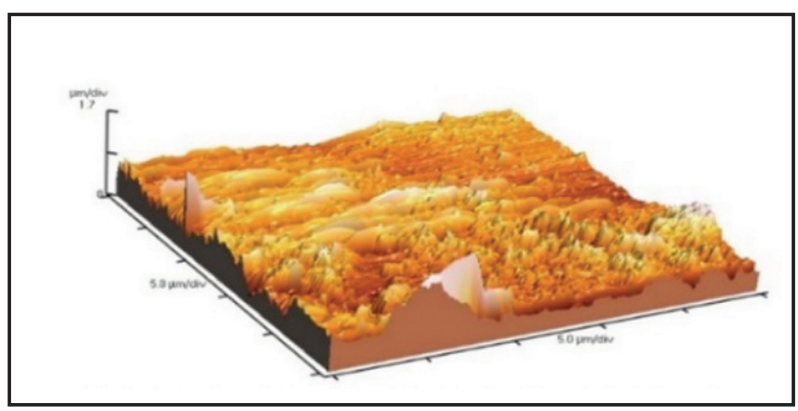

Figure (6) 3-D microphotograph of Gl after brushing with Colgate for 2240 cycles with mean surface roughness (Ra) $-190.70 \mathrm{~nm}$.

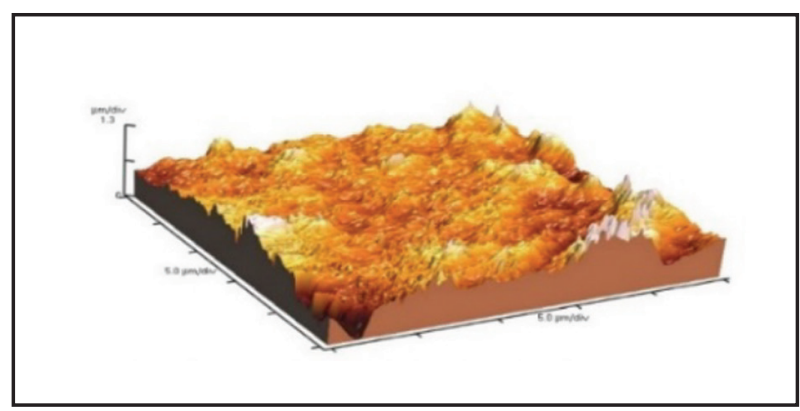

Figure(8) 3-D microphotograph of Gl after brushing with Close up for 2240cydes with mean surface roughness $(\mathrm{Ra})=169.20 \mathrm{~nm}$.

recorded $(10.07 \pm 0.077)$, followed by Calcium carbonate containing tooth paste (8.13 \pm 0.52$)$, then trisodium phosphate containing tooth paste $(6.09 \pm 0.35)$ also brushing for eight weeks (2240cycles) revealed significant change in color as shown in table (4). 
Table (4): The mean, standard deviation (SD) values and level of significance $(p<0.05)$ of color of different tooth pastes in different groups.

\begin{tabular}{|c|c|c|c|c|c|c|}
\hline \multirow{2}{*}{ Variables } & \multicolumn{5}{|c|}{ Composite } & \multicolumn{2}{c|}{ GI } \\
\cline { 2 - 7 } & \multicolumn{3}{|c|}{ Color } \\
\cline { 2 - 7 } & Close up & Colgate & Signal & Close up & Colgate & Signal \\
\cline { 2 - 7 } & Mean \pm SD & Mean \pm SD & Mean \pm SD & Mean \pm SD & Mean \pm SD & Mean \pm SD \\
\hline After 1120 cycles & $1.34^{\mathrm{b}} \pm 0.23$ & $2.04^{\mathrm{b}} \pm 0.29$ & $2.86^{\mathrm{b}} \pm 0.07$ & $2.63^{\mathrm{b}} \pm 0.60$ & $3.11^{\mathrm{b}} \pm 0.20$ & $4.83^{\mathrm{b}} \pm 0.39$ \\
\hline After 2240 cycles & $2.76^{\mathrm{a}} \pm 0.40$ & $5.03^{\mathrm{a}} \pm 0.02$ & $7.02^{\mathrm{a}} \pm 0.57$ & $6.19^{\mathrm{a}} \pm 0.35$ & $8.13^{\mathrm{a}} \pm 0.52$ & $10.07^{\mathrm{a}} \pm 0.77$ \\
\hline p-value & $\mathbf{0 . 0 0 6}^{*}$ & $<\mathbf{0 . 0 0 1 *}$ & $<\mathbf{0 . 0 0 1}^{*}$ & $\mathbf{0 . 0 0 1}^{*}$ & $<\mathbf{0 . 0 0 1 *}$ & $<\mathbf{0 . 0 0 1}^{*}$ \\
\hline
\end{tabular}

Means with different letters states for significant difference, mans with the same letter's states for non-significant difference. *; significant $(p<0.05) \quad n s ;$ non-significant $(p>0.05)$

\section{DISCUSSION}

Tooth colored restorative materials are commonly used in dentistry as aesthetic filling materials and also for conservative procedures. Nano-filled resin composite was developed using advanced sol-gel technology to produce nanofiller particles that allowed higher nanofiller ratio compared to the conventional composites. High overall filler content in excess of $79 \mathrm{wt} \%$ of nano filler is responsible for high esthetic properties, polish retention, gloss, hardness, high wear resistance and good mechanical properties ${ }^{(17)}$. Recently, an encapsulated Equia forte glass ionomer system which is composed of high viscosity glass ionomer with nano filled resin coat had been introduced to the market with high mechanical properties that can restore class I and II cavities as amalgam and composite ${ }^{(18)}$. Micro hardness, surface roughness and color are more important factors to be considered for success of any filling material. With low surface hardness the material is susceptible for scratches and lead to failure of restorative materials. Rough Surface can lead to staining of material and discoloration, which may compromise the esthetic of restoration. Thus, it is very important to know the effect of abrasive containing whitening tooth paste on physical properties of restorative materials ${ }^{(\mathbf{1 9}, \mathbf{2 0})}$.
The brushing procedures were conducted using toothbrush simulator machine in order to standardize strokes with uniform pressure. The number of brushing cycles performed in this study was based on simulation of normal clinical condition which equal 40 cycles per day ${ }^{(21,22)}$.Vickers hardness tester was chosen for this study because it is less sensitive to textures (surface conditions) and surface effects and more sensitive to measurement errors when equal loads are applied due to its shorter diagonals $(23,24)$. Profilometry is more accurate than measuring the mass loss of samples and so that it is among the most popular methods used worldwide for abrasion studies. The CIE $L^{*} a^{*} b^{*}$ coordinate system was selected to evaluate the color change $(\Delta \mathrm{E})$ as it is applicable for the determination of small color changes and has advantages such as repeatability, objectivity and sensitivity ${ }^{(25,26)}$.

Regarding restorative materials, Filtek Z350 exhibited greater VHN means, lowest roughness and greater color stability than Glass ionomer, both before and after brushing. This result could be explained by difference in composition and filler particles content of each material. Nanofilled composite has nanoparticles of 5-20nm and 79wt\% fillers in composition ${ }^{(27)}$, higher filler ratio of nanofilled composite might explain the higher VHN 
means, also might be attributed to the presence of nano fillers and nano clusters which could affect the light reflection and hence the degree of conversion. The zirconia and silica fillers in the Filtek Z350XT have greater hardness and less solubility when compared with fillers in glass ionomer. However, the lower hardness of glass ionomer system could be related to lower filler content than nano filled composite and higher filler size of the nano-filled coating contain (10-15\%) silica fillers with particle size 30-40 nm which is larger than fillers of filtek Z350 ${ }^{(14)}$. Due to these characteristics of filler's size and content, filtek Z350 composite recorded the highest significant hardness, lowest roughness as shown in (Tables 1\&2) respectively. This result is in accordance with previous studies ${ }^{\left(\mathbf{2 8},{ }^{29}\right)}$ where authors have reported increased micro hardness in composite with small particles size and uniform distribution of filler content when compared to composite with larger particles and contain mixture of irregular and rounded filler particles.

Regarding the effect of tooth pastes, hydrated silica containing tooth paste showed statistically the least micro hardness, highest roughness value and least color stability followed by calcium carbonate containing tooth paste and trisodium phosphate containing tooth paste this might be due to difference in hardness number of the abrasive particles according to Mohs scale that is established to measure the hardness of dental structure and the hardness of abrasive agents, the harder the abrasive particles the more the fillers are abraded and more exposure of inner weak layers of material ${ }^{(30,31)}$.The results of our study was in consistence with investigators who stated that hydrated silica containing tooth paste produced greater increase in roughness and more change in color of nano filled composite than tooth paste containing calcium carbonate abrasive particles ${ }^{(\mathbf{3 2})}$. However, this result was in controversy with that of other authors who stated that calcium carbonate containing tooth paste produce greater increase in surface roughness than that containing hydrated silica and they explained their results that tooth paste containing calcium carbonate has lower relative dentine abrasive capacity than that contain hydrated silica $^{(33)}$.

After brushing for 1120 cycles, hydrated silica containing tooth paste gave the greatest reduction in micro hardness in both resin composite and glass ionomer. This might be because hydrated silica has greater hardness number than calcium carbonate and trisodium phosphate. Initially at 1120 cycles the abrasive particles removed protruded fillers from esthetic restorative materials and gave reduction in micro hardness value. With increasing brushing cycles to 2240 cycles removed extra fillers produced high decreasing in micro hardness ${ }^{(34)}$.The results of our study was in agreement with some investigators who compared the effect of whitening dentifrices on the surface hardness of a nano hybrid composite, they found that maximum reduction in micro hardness was produced by whitening paste contains silica as the abrasive agent ${ }^{(32)}$.

Brushing for 2240cycles showed highest color change that might be explained by the gradual loss of material, representing increasing deterioration action of tooth brushing on the material due to removal of fillers from resin composite and subsequent discoloration tendency ${ }^{(35)}$.Composite "plasticization' 'that decreases the hardness of the polymeric matrix and can be used to justify the color change of composite as nano filled composite contain TEGDMA monomer that has greater tendency to water sorption, increasing aqueous solubility of the polymer formed due to increase in polymer free volume, enabling more space for water molecules to diffuse into the polymeric structure ${ }^{(36,37)}$. Hydrated silica containing tooth paste showed highest color change in both restorations followed by calcium carbonate containing tooth paste then trisodium phosphate containing tooth paste that recorded the least color change. This could be explained by the presence of extra ingredient called perlite. It is an amorphous mixed glossy silicate of volcanic origin which has neutral PH, chemically inert and well 
known for its use in prophylactic pastes where it has been shown to exhibit excellent polishing and cleaning properties. In addition, the combination of silica and perlite in toothpaste has been demonstrated to have significant stain removal and prevention benefit in a clinical study ${ }^{(38)}$.

\section{CONCLUSION}

Abrasive containing Whitening dentifrices and number of brushing cycles have an influential effect on surface characteristics and color stability of composite and glass ionomer.

\section{REFERENCES}

1. Borges A, Caneppele T, Luz M, Pucci C, Torres C. Color stability of resin used for caries infiltration after exposure to different staining solutions. Oper Dent. 2014; 39: 433-40.

2. Hengtrakool C, Kukiattrakoon B, Kedjarune-Leggat U. Effect of naturally acidic agents on microhardness and surface micromorphology of restorative materials. Eur J Dent. 2011; 5:89-100.

3. Torres CR, Da Silva TM, Sales AL, Pucci CR, Borges AB. Influence of chemical degradation and tooth brushing on surface of composites. World J Dent. 2015; 6:65-70.

4. Philpotts CJ, Weader E, Joiner A. The measurement in vitro of enamel and dentine wear by toothpastes of different abrasivity. Int Dent J. 2015; 55: 183-7.

5. Moraes RR, Ribeiro D S, Klumb MM, Brandt WC, CorrerSobrinho L, Bueno M. In vitro tooth brushing abrasion of dental resin composites: packable, microhybrid, nanohybrid and microfilled materials. BrazOra Res. 2008; 22:112-8

6. Bolay S, Cakir FY, Gurgan S. Effects of tooth brushing with fluoride abrasive and whitening dentifrices on both unbleached and bleached human enamel surface in terms of roughness and hardness: An in vitro study. J Cont Dent Pract. 2012; 13:584-9.

7. Mitra SB, Wu D, Holmes BN. An application of nanotechnology in advanced dental materials. J Am Dent Assoc. 2013; 134:1382-90.

8. Bonifacio CC, Werner A, Kleverlaan CJ. Coating glassionomer cements with a nanofilled resin Acta Odont Scan. 2012; 70:471-7.
9. Diem VTK, Tyas MJ, Hien CN, Phuong LH, Khanh ND. The effect of a nano-filled resin coating on the 3 year clinical performance of a conventional high-viscosity glass-ionomer cement .Clini Oral Invest. 2014; 18:753-9.

10. American national standard. American Dental Association Specifications no. 27 for Resin-based filling materials, 1993.

11. Manis R, Franco T, Franco L, Huhtala M. "Influence of whitening toothpaste on color, roughness, and micro hardness of composite resins. J Euro Gen Dent .2018; 6: 174-90.

12. Hilgenberg SP, Pinto SC, Farago PV, Santos FA, Wambier DS. Physical-chemical characteristics of whitening toothpaste and evaluation of its effects on enamel roughness. Braz Oral Res. 2011; 25:288-94.

13. John DP,Jayasree S. Comparison of the Effects of Different Toothpastes on the Micro Hardness of a Nano Hybrid Composite Resin - An in-Vitro Study. IOSR J of Dent and Medi Sci .2017; 16: 06-11.

14. Fakieh A, Al-Yamani D, Badr N .Tribological and Topographical Characteristics of Nano-Processed Coating for Aesthetic Restorative Materials .J Int .2018; 10:82532.

15. Al-Shalan T. Effect of whitening toothpastes on color stability of different restorative materials. J Int of Medi Sci and CliniInve. 2017; 4:790-6.

16. International Standards Organization. Technical specification 14569-1. Dental materials-guidance on testing of wear resistance. Part 1: wear by tooth brushing. Switzerland: International Standards Organization; 1999.

17. Jin J, Takahashi R, Hickel R, Kunzelmann KH. Surface properties of universal and flowable nano hybrid composites after simulated tooth brushing. Am J Dent. 2014; 27:149-54.

18. Gurgan S, Kutuk ZB , Ergin E.Four-year Randomized Clinical Trial to Evaluate the Clinical Performance of a Glass Ionomer Restorative System.Oper J Dent.2015; 10:40-9.

19. Claydon NA, Moran J, Bosma ML, Schirodaria S, Addy M, Newcombe R. Clinical study to compare the effectiveness of a test whitening toothpaste with a commercial whitening toothpaste at inhibiting dental stain. J ClinPerio. 2004; 31:1088-91.

20. Meyers IA, McQueen MJ, Harbrow D, Seymour GJ. The surface effect of dentifrices. Australian Dent. 2010; $45: 118-4$. 
21. Rocha AD, Lima CS, Santos MD, Montes MA. Evaluation of surface roughness of a nanofill resin composite after simulated brushing and immersion in mouth rinses, alcohol and water. Mater Res. 2010; 13: 77-80.

22. Wiegand A, Kuhn M, Sener B, Roos M, Attin T. Abrasion of eroded dentin caused by toothpaste slurries of different abrasivity and toothbrushes of different filament diameter. J Dent 2009; 37:480-4.

23. Attin T, Hannig C, Wiegand A, Attin R. Effect of bleaching on restorative materials and restorations- $\mathrm{A}$ systemic review. Dent Mater. 2004; 20:852-81.

24. Khamverdi Z, Kasraie SH, Rezaei-Soufi L, Jebeli S. Comparison of the effects of two whitening toothpastes on micro hardness of the enamel and a microhybrid composite resin: An in vitro study. J Dent 2010; 7:139-5.

25. Barbakow F, Lutz F, Imfeld T. A review of methods to determine the relative abrasion of dentifrices and prophylaxis pastes. Quint Int 1987; 18:23-8.

26. Jain V, Platt JA, Moore K, Spohr AM, Borges GA. Color stability, gloss and surface roughness of indirect composite resins. J Oral Sci. 2013; 55:09-15.

27. Abuelenain DA, Neel EAA, Al-Dharrab A. Surface and mechanical properties of different dental composites. Austin J Dent. 2015; 2:10-19.

28. Festuccia MS, Garcia LF, Cruvinel DR, Pires-De-Souza FC. Colour stability, surface roughness and microhardness of composites submitted to mouth rinsing action. J Appl Oral Sci. 2012; 20:200-5.

29. Agarwal PK, Parmar P. Study of micromechanical properties of PP4/SWCNT/PVA composites using Vicker's micro hardness testing. Ultra Scientist. 2014; 26:235-42.

30. Hefferren J. Critical points in the evolution of laboratory methods to measure the functionality of toothpastes. J Clin Dent. 2010; 21:6.

31. Bailey SJ, Swift EJ. Effects of home bleaching products on composite resins. J Quint Int. 1992; 23:489-44.

32. Thomas Nainan TM, Balan AK, SharmaR.The comparison of the effects of different whitening toothpastes on the micro hardness of a nano hybrid composite resin. J Clin Dent. 2014; 17: 550-4.

33. Roselino LM,Chinelatti MA, Alandia-Roman CC. Effect of Brushing Time and Dentifrice Abrasiveness on Color Change and Surface Roughness of Resin Composites. Braz Dent. 2015; 26:40-4.

34. Bailey SJ, Swift EJ. Effects of home bleaching products on composite resins. J Quint Int. 1992; 23:489-94.

35. Silva EMD, Maia JN, Mitraud CG, Russo JD, Poskus LT. Can whitening toothpastes maintain the optical stability of enamel over time?.J Appl Ora Sci.2018; 26:16-46.

36. Vichi A, Ferrari M, Davidson CL. Color and opacity variations in three different resin based composite products after water aging. Denl Mater 2004; 20:530-4

37. Erdemir U, Yildiz E, Eren MM. Effects of sports drinks on color stability of nanofilled and microhybrid composites after long-term immersion. J Dent 2012; 40:55-63.

38. Debner T, Warren DP, Powers JM. Effects of fluoride varnish on color of aesthetic restorative material. J Aest Dent. 2000; 12:160-3. 